\title{
Hamstring Injuries Prevention in Soccer: A Narrative Review of Current Literature
}

\author{
Gian Nicola Bisciotti ${ }^{1}$ Karim Chamari ${ }^{1}$ Emanuele Cena ${ }^{1}$ Giulia Carimati ${ }^{2}$ Alessandro Bisciotti ${ }^{3}$ \\ Andrea Bisciotti $^{3}$ Alessandro Quaglia ${ }^{2}$ Piero Volpi ${ }^{2,4}$ \\ ${ }^{1}$ Qatar Orthopaedic and Sport Medicine Hospital, FIFA Center of \\ Excellence, Doha, Qatar \\ 2 Orthopedic Knee and Sports Traumatology Department, Humanitas \\ Address for correspondence Gian Nicola Bisciotti, PhD, Qatar \\ Orthopaedic and Sport Medicine Hospital, FIFA Center of Excellence, Doha, \\ Research Hospital, Rozzano, Italy \\ ${ }^{3}$ Centro Studi Kinemove, Pontremoli, Italy \\ ${ }^{4}$ FC Internazionale, Milan, Italy
}

Joints 2019;7:115-126.

\begin{abstract}
Keywords

- injury mechanism

- risk factors

- anatomical location

- biomechanics

Hamstring injuries and reinjuries are one of the most important sport lesions in several sport activities including soccer, Australian football, track and field, rugby, and in general in all sport activities requiring sprinting and acceleration. However, it is important to distinguish between the lesions of the biceps femoris and semitendinosus and semimembranosus. Indeed, three muscles representing the hamstring complex have a very different injury etiology and consequently require different prevention strategies. This fact may explain, at least in part, the high incidence of reinjuries. In soccer, hamstring injuries cause an important rate of time loss (i.e., in average 15-21 matches missed per club per season). The hamstring injury risk factors may be subdivided in three categories: "primary injury risk factors" (i.e., the risk factors mainly causing a first lesion), "recurrent injury risk factors" (i.e., the risk that can cause a reinjury), and bivalent injury risk factors" (i.e., the risk factors that can cause both primary injuries and reinjuries). The high incidence of hamstring lesions caused consequently an important increase in hamstring injury research. However, although the prevention has increased paradoxically, epidemiological data do not show a loss in injuries and/or reinjuries but, on the contrary, they show an increase in hamstring injuries. This apparent paradox highlights the importance both of the improvement in the prevention programs quality and the criteria for return to play after hamstring injury.
\end{abstract}

\section{Introduction}

Hamstring muscle tears are frequent injuries in professional soccer players ${ }^{1-4}$ representing on average $17 \%$ of all soccer injuries. ${ }^{2,5}$ The severity of the issue ranges from delayed onset muscle soreness to a complete muscle tear. ${ }^{6}$ In soccer, the risk of a hamstring injury is 2.5 greater than an injury to the quadriceps muscle. ${ }^{7}$ A professional soccer team records on average a rate of 10 hamstring strain injuries per season. ${ }^{8,9}$ This means approxi- mately 90 days of time loss due to injury and on average 15 to 21 matches missed per club per season., ${ }^{4,10,11}$ In terms of exposure, the hamstring injuries incidence is 0.87 to $0.96 / 1,000$ hours. $^{12}$

The hamstring injuries represent an important problem not only in soccer. In Australian football, hamstring injuries are the cause of approximately $20 \%$ of all missed games, ${ }^{13}$ in track and field the incidence ranges between 10 and $14 \%,{ }^{14-16}$ and in rugby between 6 and 15\%. ${ }^{17-19}$ Hamstring injuries are also common in dancing, ${ }^{20}$ waterskiing, ${ }^{21}$ and received

November 4, 2017 accepted after revision

April 13, 2020

published online

May 25, 2020
DOI https://doi.org/ $10.1055 / \mathrm{s}-0040-1712113$. ISSN 2282-4324.

\footnotetext{
(C) 2020. The Author(s).

This is an open access article published by Thieme under the terms of the Creative Commons Attribution-NonDerivative-NonCommercial-License, permitting copying and reproduction so long as the original work is given appropriate credit. Contents may not be used for commercial purposes, or adapted, remixed, transformed or built upon. (https://creativecommons.org/ licenses/by-nc-nd/4.0/) Georg Thieme Verlag KG, Rüdigerstraße 14, 70469 Stuttgart, Germany
} 
cricket, $^{22}$ for instance. A recent study ${ }^{23}$ reported a 13 -year longitudinal analysis of the Union of European Football Associations (UEFA) Elite Clubs. Results show that, since 2001, hamstring injuries increased by approximately $4 \%$ annually in training while remain roughly constant in matches. A possible explanation for it is that during training sessions higher intensity exercises with and without ball are performed to reproduce the match intensity model. In other words, the intensity of the training session is becoming very similar to the intensity of the match. This of course causes an increased risk of hamstring injuries. Conversely, the hamstring injury recorded during matches, since 2001, remained almost constant. This might depend on the high intensity of the training sessions that make the players better prepared to cope with the match intensity.

Although in the last years, there has been much more attention in implementing hamstring prevention programs, its important underline that hamstring injuries are still increasing. This is not surprising if we consider the fact that the increase in hamstring prevention programs is probably counteracted by an increasing, over the last years, of the intensity both of trainings and matches. ${ }^{23}$ About this topic, Barnes et $\mathrm{al}^{24}$ showed that in the English Premier League from 2006 to 2013 seasons over the years there was a 30 and 35\% increase respectively in high-intensity running distance and number of sprints during the matches.

The common denominator of hamstring injury risk in these sport activities could be the high running speed required during the game ${ }^{4,12,19,25-28}$ and the sudden stops, restarts/reaccelerations, and/or sudden changes of direction. ${ }^{1,29}$ Furthermore, the percentage of reinjuries is high ranging from 12 to $63 \%{ }^{4,19,30}$ with a peak of incidence during the first 3 weeks after return to play (RTP). ${ }^{10}$

For all these reasons, hamstring injuries can often be impacting or even dramatic for the players' career.

\section{Injury Mechanisms}

Hamstring injuries occur in sport activities requiring sprinting, cutting movements, acceleration efforts, ${ }^{1,10,31-34}$ and extreme stretch movements. ${ }^{35}$ However, within the hamstring muscular complex it is important to split the injury mechanisms into biceps femoris (BF), semimembranosus (SM), and semitendinosus (ST) muscles lesions. The hamstring muscular complex during the running biomechanics is active from the beginning of the mid-swing phase until the terminal stance phase. ${ }^{1,36,37}$ During this period of time, the $\mathrm{BF}$ is the muscle that undergoes the most elongation, equal to approximately $12 \%$ of its rest length. ${ }^{34,38-41}$ In the same phase, the SM is the flexor muscle producing the most important strength peak and absorbing the most important parts of the power production. ${ }^{34,38-41}$ For these reasons, the BF and SM injuries are substantially different. ${ }^{35,42,43}$ In other words, the BF injury mechanism is mainly based on an overstretching event, while the SM injuries are mainly based on a strength/power overproduction. ${ }^{35,42,43}$

Biomechanics of ST is more complex. Both ST and BF show the maximal eccentric activation throughout the swing phase of running (i.e., from middle swing to initial stance phase). ${ }^{41,44,45}$ Furthermore, a recent study showed that ST has the highest strength production activity as it is recruited more than both the BF and the SM in strength exercises. ${ }^{46}$ Despite this, the ST is the muscle of hamstring complex that presents the lower injury incidence, equaling 5 to $6 \%{ }^{47-49}$ This low injury incidence may be explained by its important tendinous component playing a protective role against indirect injuries. $42,43,47,50,51$

\section{Risk Factors}

According to Brukner et al, ${ }^{52}$ we will subdivide the hamstring injury risk factors into "primary injury risk factors" (i.e., the risk factors mainly causing a first lesion) and "recurrent injury risk factors" (i.e., the risk that can cause a reinjury). In addition to these two categories, we will describe some injury risk factors playing a role both as "primary injury risk factors" and "recurrent injury risk factors." We have listed these latter into the category called "bivalent injury risk factors."

The primary injury risk may be divided into nonmodifiable and modifiable risk factors.

\section{Nonmodifiable Primary Injury Risk Factors}

\section{Age}

One of the most important nonmodifiable risk factors is represented by the chronological age. ${ }^{4,53-55}$ Several authors showed that increasing age is one of the most important risk factors especially when coupled with previous injuries. $4,27,52-54,56,57$

Verrall et $\mathrm{al}^{53}$ showed that, starting from around 20 years of age, the likelihood of a hamstring injury increases by 1.3 times every year, independently of a past history of hamstring injuries. Hägglund et $\mathrm{al}^{57}$ showed that the association between increased age and previous hamstring injuries represents a significant hamstring risk factor in a multivariate model analysis.

\section{Previous Injuries (Nonhamstring Related)}

Previous injuries not involving the hamstring may be a risk factor for primary hamstring injury. Major knee injuries, like ipsilateral anterior cruciate ligament reconstruction (independently from the type of graft used) $47,53,58,59$ or a previous history of osteitis pubis, ${ }^{53}$ may increase the risk of hamstring strains independently from previous posterior thigh injuries.

\section{Ethnicity}

Woods et $\mathrm{l}^{4}$ showed that professional black soccer players had higher risk for primary hamstring injuries than white players. These results are in line with results collected by Verrall et $\mathrm{al}^{53}$ showing that Australian Rules football players with aboriginal origins had higher primary hamstring injury risks compared with the others. Woods et $\mathrm{al}^{4}$ explained this ethnicity risk factor subjects with a black ethnic origin having an increased anterior pelvis tilt which overstretches the hamstring complex and exposes the subjects to a higher injury risk. This theory is in line with other more recent studies. ${ }^{8,9}$ Concerning the 
increased injury risk for aboriginal descent players, other authors $^{53}$ proposed that they may have proportionately more hamstring type-II muscle fibers and for this reason have a higher primary risk for hamstring injuries. ${ }^{60,61}$ This theory was later confirmed by other studies. ${ }^{55}$

\section{Competition Level}

A higher competition level represents a risk factor for primary hamstring Injury. ${ }^{4,53}$ This relationship between competition level and hamstring injuries may reflect the increased physical demand and the related powerful play actions existing in higher level leagues. Furthermore, we must consider that a high competition level leads to a higher match exposure time causing a decrease in the training exposure/match exposure relationship and resulting in a higher injury risk for the athletes. 8,9

\section{Latest Periods of Soccer Matches}

Some studies showed an increased hamstring injury risk (particularly primary injuries) at the end of each half of the match. 1,3,4,8,9,62 Other studies reported that the peak of soccer injuries (including the primary hamstring injuries) occur during the second half of the match. ${ }^{1,63,64} \mathrm{~A}$ possible reason for that is the hamstring eccentric strength decrease as a function of time after the halftime of the match. ${ }^{62}$ This eccentric strength loss would determine a higher injury risk especially during explosive movements, in accordance with epidemiologic observations. ${ }^{62}$ However, it should be underlined that in the literature some similar studies did not confirm these results. $54,56,65$

\section{Modifiable Primary Injury Risk Factors}

\section{Hamstring Muscle Strength Imbalance Profile}

An unbalanced ratio between hamstring concentric strength and quadriceps concentric strength (hamstring con/Q con) measured at low $\left(60^{\circ} / \mathrm{s}\right)$ or fast $\left(240^{\circ} / \mathrm{s}\right)$ angular speed is classically considered an hamstring injury risk factor. This hypothesis means that an insufficient strength of the hamstring complex is not able to effectively counteract both the action of hip flexion performed by the quadriceps and the subsequent swing phase during the sprint biomechanics. ${ }^{66-69}$ In literature, an appropriate hamstring con/Q con ratio measured at low $\left(60^{\circ} / \mathrm{s}\right)$ or fast $\left(240^{\circ} / \mathrm{s}\right)$ angular speeds is comprised between 0.48 and 0.65 . $^{67-70}$ Aagaard et $\mathrm{al}^{71}$ proposed a 1:1 ratio based on hamstring eccentric strength/quadriceps concentric strength (hamstring ecc/Q con) as a correct ratio value. This hamstring ecc/Q con ratio seems to our opinion more interesting than the classical hamstring con/Q con for two specific reasons: (1) this ratio shows better functional capacity of the hamstring providing knee-joint stability since the latter is mainly due to the hamstring eccentric strength ${ }^{59}$; (2) hamstring ecc/Q con ratio take into account the fact that during the movement in which the hamstring injury risk is increased, the hamstring activation is of eccentric type $\mathrm{e}^{34,38-41}$ and it is therefore more specific than the classic hamstring con/Q con ratio.

\section{Recurrent Injury Risk Factors}

The recurrent injury risk factors (or reinjury risk factors) may as well be divided into nonmodifiable risk factors and modifiable risk factors.

\section{Nonmodifiable Recurrent Injury Risk Factors}

\section{History of Hamstring Injury}

A history of previous hamstring injuries is considered the most important risk factor for hamstring reinjuries. $27,47,53,54,56,72-82$ An interesting study ${ }^{79}$ showed that players previously affected by a soccer injury doubled the risk of having a second injury; furthermore, the risk of reinjury decreased in relation to the time spent from the last injury occurred. Another study ${ }^{75}$ pointed out that a player with a soccer injury in the previous season had an injury risk three times greater, during the successive season, than the players not injured in the previous season. Finally, it is important to underline that a muscle reinjury causes a longer "injury time loss" than the first injury event. ${ }^{8,9,28}$

\section{Size of Injury}

A larger size of hamstring injury measured through magnetic resonance imaging $(\mathrm{MRI})^{47,83}$ was indicative of a higher recurrent injury risk. ${ }^{83}$ Therefore, the strain length measured by MRI may identify which athletes are more likely to suffer further reinjury. ${ }^{47}$ However, other studies challenged this result. ${ }^{84}$ Therefore, there is a need of further studies with more evidences.

\section{Modifiable Recurrent Injury Risk Factors}

Inadequate Rehabilitation Programs

It has been suggested that a premature RTP, ${ }^{4,14,70,85-87}$ an inappropriate and/or insufficient rehabilitation program, $4,70,73,85,88$ or an association of these two factors may be responsible for hamstring reinjury.

\section{Change in Optimal Muscle Length}

A difference in the length-tension relationship, measured by isokinetic test, may be a risk factor for reinjuries. ${ }^{89}$ Indeed, after the first injury, the presence of excessive scar tissue can reduce the optimal muscle length predisposing it to reinjury. ${ }^{90,91}$

\section{Bivalent Injury Risk Factors}

The bivalent injury risk factors are essentially modifiable risk factors.

\section{The Hamstring Weakness}

Inadequate hamstring strength and/or endurance measured by isokinetic test is indicated by some authors as a risk factor for hamstring indirect primary injuries and/or reinjuries. ${ }^{85,92-94}$ However, some studies show conflicting results. ${ }^{95}$ This difference can be explained by several reasons: (1) The difference in isokinetic protocols used at different executive speed generally comprised between 30 and $300^{\circ} /$ second. $^{96,97}$ 
Such a wide difference in the study protocols makes the results difficult to compare. (2) Strength is not the only parameter to be considered concerning muscle functionality. Indeed, a muscle after injury may also have recovered good dynamometric strength values but it may still have some flexibility deficit and/or to present excessive fibrotic areas that put it still at risk of reinjury. (3) The torque strength values do not represent accurately the muscle behavior in extreme dynamic situation as in the case of sporting gestures. ${ }^{98,99}$

\section{Loss of Extensibility}

Several authors indicated an extensibility loss as a risk factor for hamstring indirect injuries. ${ }^{85,92-94,100}$ However, in literature some studies do not confirm these data. ${ }^{54,56,101,102}$

An interesting study ${ }^{103}$ showed that soccer teams using stretching regularly in their training routine have a less hamstring injuries incidence. These data confirm, even though indirectly, the important role of flexibility in hamstring injuries prevention. Indeed, stretching and/or eccentric exercises may induce an augmentation of the optimal muscle length to which the muscle can perform the different level of strength required during physical activity. ${ }^{104}$ This increased optimal length may result in improving the muscle structural stability. This is especially valid at longer muscle length, making protective factor for muscle injuries that can occur during the eccentric lengthening to which the muscle is subjected during sport activity. ${ }^{105}$ It is interesting to note that hamstring flexibility shows an U-inversed shaped relationship with the injuries incidence. ${ }^{106}$ In other words, the incidence of hamstring injuries is recorded at both the two extremes of flexibility (i.e., the subjects too rigid and overly flexible). Therefore, being too flexible, in part for some sports activities such as gymnastics or dance in which it is required a maximum range of motion, could increase the injury risk. It is therefore reasonable to assume that there is an optimal degree of flexibility below and above which the risk factor is increased.

\section{Pelvic Muscles Coordination}

Core stability and strength training of the pelvic muscles have been popular in recent years, providing benefits for reducing the hamstring injury risk. ${ }^{107-109}$ Consequently, a loss of core stability due to a weakness of pelvic muscles would be an injury risk factor both for primary hamstring injuries and reinjuries. ${ }^{107-109}$ Indeed, the pelvic movements change the relative length and consequently the stiffness of hamstring complex, for this reason an insufficient strength of pelvic muscles and/ or their incorrect intervention time may represent a risk factor. ${ }^{51}$

\section{Training Mistakes and Inadequate Warm-Up}

Several studies showed that mistakes in training plans $^{98,99,101,102,110}$ and insufficient warm-up ${ }^{100,111-114}$ are risk factors for hamstring injuries. However, errors in training plans are so different and heterogeneous to be classified. Instead, concerning the role of warm-up in hamstring injuries prevention, a reasonable explanation is that adequate warmup is able to reduce muscle viscosity and to induce a neural relaxation of the muscle. ${ }^{98,99,110-114}$

\section{Fatigue}

The fatigue, either immediate (i.e., during a match) or in long term (i.e., accumulated in more competitions), may represent a risk factor. The fatigue effect can interfere negatively with technical and coordination skills, as well as with the decision-making process involving the opponent and the ball, thus causing an imperfect actions' timing potentially dangerous. As previously mentioned, the injury risk in the fatigued player, during explosive movements such as sprinting or cutting, is proportional/dependent upon the increased fatigue effect. ${ }^{62,115}$ Concerning the so-called "long-term fatigue effect" in literature, there are some studies showing that the congested fixture periods, with a match every 3 days, and the consequently a high "match time exposure," determine a great increase of injuries risk. ${ }^{116}$ Consequently, whenever possible, an appropriate players' turnover could lower the injury rate. ${ }^{116} \mathrm{~A}$ further demonstration of these data comes from the study of Bengtsson et $\mathrm{al}^{117}$ conducted in 27 soccer professional clubs over 11 seasons. In this study, the global number of soccer injuries, and especially muscle indirect injuries, regularly increased when the recovery time between two matches was less than 4 days compared with 6 days or more. The onset of fatigue may be delayed by specific training. ${ }^{118,119}$ However, an improvement in the fatigue threshold induces the athlete to be able to reach a higher intensity of effort. ${ }^{120,121}$

\section{The Rationale of Prevention Programs}

Prevention programs are possible when a risk management plan is implemented at the club, consisting primarily on an injury surveillance program, a subsequent objective evaluation and thereafter actions to correct the eventual observed issues. $^{122}$

Hamstring injury prevention programs are based on stretching, ${ }^{103,123-127}$ strengthening (especially concerning the eccentric force), ${ }^{55,82,128-132}$ hamstring/Q ratio rebalancing, ${ }^{67}$ hamstring bilateral ratio rebalancing, ${ }^{67,133}$ and multiintervention programs (i.e., prevention programs based on strengthening, stretching, elasticity, core stability, proprioception, and neuromuscular exercises). ${ }^{125,134,135}$

Concerning the hamstring injury prevention programs based on stretching the results are conflicting. It is interesting to note that randomized controlled trials (RCTs) showed that stretching does not reduce the incidence of hamstring injuries while non-RCTs showed a reduction in injuries after stretching. This suggests an important Coleman effect ${ }^{136}$ that makes difficult to draw robust conclusions. Furthermore, the study protocols are very different both regarding intervention duration and follow-up. More evidence-based studies are therefore needed to assess the effectiveness of the prevention program based on stretching to reduce hamstring injuries.

On the contrary, the programs based on strengthening, ${ }^{27,82,128-132}$ hamstring/Q rebalancing, ${ }^{67}$ hamstring bilateral ratio rebalancing, ${ }^{67,133}$ and multi-intervention programs ${ }^{125,134,135}$ have demonstrated their effectiveness in decreasing hamstring injuries. Furthermore, it is 
Table 1 NHE training schedule proposed by Mjølsnes et al ${ }^{168}$

\begin{tabular}{|c|c|c|c|c|}
\hline Week & $\begin{array}{l}\text { Weekly } \\
\text { sessions }\end{array}$ & Sets & Reps & Load \\
\hline 1 & 1 & 2 & 5 & \multirow{5}{*}{$\begin{array}{l}\text { The load increase is } \\
\text { allowed only when the } \\
\text { athlete is able to easily } \\
\text { control the eccentric } \\
\text { phase. When the ath- } \\
\text { lete reaches } 12 \text { repeti- } \\
\text { tions the load can be } \\
\text { increased through:( } 1) \\
\text { an increase of the initial } \\
\text { speed, }(2) \text { with a push at } \\
\text { the shoulder level } \\
\text { carried by the partner }\end{array}$} \\
\hline 2 & 2 & 2 & 6 & \\
\hline 3 & 3 & 3 & $6-8$ & \\
\hline 4 & 3 & 3 & $8-10$ & \\
\hline $5-10$ & 3 & 3 & $12-10-8$ & \\
\hline
\end{tabular}

Abbreviation: NHE, Nordic hamstring exercise.

important to mention the importance of core stability training in hamstring injury prevention programs. ${ }^{107-109}$

Paradoxically, despite these data, the epidemiological studies focusing on hamstring injuries and reinjuries demonstrate that these latter show no decline with time. ${ }^{8,9,137}$ A more recent study showed that in the UEFA Champions League, the hamstring injury rate increased $4 \%$ per year. ${ }^{23}$ This incongruence may be explained by the possible inadequacy of rehabilitation programs and poorly defined criteria concerning RTP. ${ }^{81,138}$ -Table 2 reports a summary of methodologies proposed for hamstring prevention found in current literature.

\section{Primary and Secondary Prevention Programs}

Primary prevention (PP) is a preventive strategy adopted to prevent a first muscle injury to occur, while the secondary prevention (SP) is a prevention strategy performed after one or more lesions to the same muscle group, to avoid recurrences. It is important to distinguish between PP and SP. Indeed, a PP program must follow general key points for any considered muscle/muscle group, while a SP program needs to take into account the number, the anatomical location, and severity of previous injuries and needs to be structured accordingly. In other words, SP must be much more personalized and specific than the PP. ${ }^{135}$

\section{The Australian Football League Experience}

An eloquent demonstration of effectiveness of hamstring prevention programs comes from the "Australian Football League" in which, thanks to the adoption of a specific prevention strategy, the incidence of hamstring reinjury in the period between 1997 and 2004 was reduced by 22 to $37 \% .^{11}$

Important in this regard is a prospective study of Verrall et al ${ }^{125}$ performed in a group of 70 Australian football players, in which the authors emphasize four interesting points related to the PP and SP of hamstring injuries.

A preseason period, comprised between 16 and 20 weeks, during which there was an emphasis on the aerobic conditioning training through running sessions between 3 and

Table 2 Summary of methodologies proposed for hamstring prevention

\begin{tabular}{|c|c|c|c|}
\hline Methodology & Effect & Scientific rationale of use & Notes \\
\hline Stretching ${ }^{103,123-125}$ & Conflicting & $\begin{array}{l}\text { Improve the absorption of } \\
\text { elongation forces by the } \\
\text { muscle-tendon unit }\end{array}$ & $\begin{array}{l}\text { In any case its inclusion in a } \\
\text { multi-intervention program is } \\
\text { recommended } 125,134,135\end{array}$ \\
\hline $\begin{array}{l}\text { Nordic hamstring } \\
\text { exercise }\end{array}$ & Good & $\begin{array}{l}\text { To improve hamstring } \\
\text { eccentric strength }\end{array}$ & $\begin{array}{l}\text { To integrate with biarticular } \\
\text { hamstring exercises }\end{array}$ \\
\hline $\begin{array}{l}\text { Specific anaerobic-lactacid } \\
\text { training } 125\end{array}$ & Sufficient & $\begin{array}{l}\text { To reproduce in controlled situations } \\
\text { the mechanical and metabolic } \\
\text { conditions predisposing to injuries }\end{array}$ & $\begin{array}{l}\text { To be used only in subjects with } \\
\text { a good specific training } 125\end{array}$ \\
\hline $\begin{array}{l}\text { Specific technical } \\
\text { training }\end{array}$ & $\begin{array}{l}\text { Insufficient / needs } \\
\text { further } \\
\text { investigations }\end{array}$ & $\begin{array}{l}\text { To reproduce in a controlled } \\
\text { situation the biomechanical } \\
\text { conditions predisposing to injuries }\end{array}$ & $\begin{array}{l}\text { May unnecessarily increase the } \\
\text { injury risk without getting any } \\
\text { benefit in terms of prevention }\end{array}$ \\
\hline EFCEP $^{34,38}$ & $\begin{array}{l}\text { Needs further } \\
\text { investigations }\end{array}$ & $\begin{array}{l}\text { To change the force-lengthening } \\
\text { relationship through an } \\
\text { optimal length }\end{array}$ & $\begin{array}{l}\text { This method may be of } \\
\text { particular interest for BF } \\
\text { injuries prevention }\end{array}$ \\
\hline $\begin{array}{l}\text { Isokinetic } \\
\text { training } 67,73,91,151,155\end{array}$ & Good & Improving hamstring strength & $\begin{array}{l}\text { For its excellent reproducibility } \\
\text { it is also a reliable reference } \\
\text { test }\end{array}$ \\
\hline Isoinertial training ${ }^{158-162}$ & Good & Improving hamstring strength & $\begin{array}{l}\text { It may cause an important } \\
\text { delayed muscular soreness and } \\
\text { therefore important loss of } \\
\text { compliance for this type of } \\
\text { training } 140,144\end{array}$ \\
\hline Endurance training $^{125}$ & Good & To maintain a good fitness level & $\begin{array}{l}\text { It represents an important } \\
\text { strategy for primary, and } \\
\text { secondary hamstring prevention }\end{array}$ \\
\hline
\end{tabular}

Abbreviations: BF, biceps femoris; EFCEP, eccentric faster contraction in elongated position.

Note: Column 2 indicates the evidence level found in the literature, while column 3 indicates notes regarding their practical application. 
$5 \mathrm{~km}$ (the authors, however, do not specify their weekly frequency), represents a training method or better a prerequisite essential to maintain a satisfactory fitness level. The authors considered this preseason strategy important for both primary and secondary hamstring prevention. ${ }^{125}$

In their preventive strategy design, Verrall et al $^{125}$ focused the training sessions on anaerobic-lactic interval training (i.e., shuttle-run over a distance of $20 \mathrm{~m}$ ). The rationale for this type of work depends on the highest percentage of hamstring injuries recorded in Australian football injuries during the acceleration phase of a sprint to reach the ball, when bending the torso forward is strongly accentuated to grab the ball during a high-speed running.

The authors ${ }^{125}$ introduced in their preventive planning a specific type of technical training based on changes of direction with the trunk bent for ball control. These exercises also included interaction with an opponent from behind, in attempt to steal the ball to the athlete performing the specific exercise. These exercises were performed twice a week for a duration of approximately 5 minutes. Also, in this case the rational of application was to create a biomechanical adaptation for such specific risk situations. In this preventive program, the athletes were constantly and systematically encouraged to perform passive stretching exercises of the hamstring at several joint degrees for at least 15 seconds. The interesting detail is represented by the fact that the players were asked for such stretching exercises especially reaching a certain degree of muscle fatigue.

The rationale for these stretching exercises is that in literature there exist some experiments performed on animal model ${ }^{115,139}$ showing how a fatigued muscle, being less able to absorb a high rate of energy during its eccentric phase, would be more exposed to a lesion compared with a not fatigued muscle. Therefore, stretching in muscular fatigue conditions would permit a substantial recovery improvement to support an eccentric load in a biologically critical situation potentially predisposing to injury.

The combination of these four main points and their systematic performance throughout the whole season significantly reduced hamstring injuries (1.3 hamstring injuries/1,000 hours of match exposure vs. 4.7 hamstring injuries $/ 1,000$ hours of match exposure in the previous season and 0.7 hamstring injuries $/ 1,000$ hours of training exposure vs. 1.7 hamstring injuries/1,000 hours of match exposure recorded during the previous season, $p<0.045$ ). The study of Verrall et al, ${ }^{125}$ besides being undoubtedly original, also shows a further interest choosing the preventive strategies that were not medicine evidence based, but logically and suitable to be pursued. The limit of this study was that in soccer rather than Australian football, this long preseason period is not possible. The authors emphasize their concept of prevention supporting their approach with a very significant phrase: "We attempt to change the specificity of the training to training as the game is played." This means that an optimal preventive model must try to follow, or at least to adapt as much as possible, the specific performance model. Another basic concept expressed by the authors is to avoid believing that a preventive work plan can be based on a single type of exercise, rather than considering prevention as a complex and multifactorial process based on the idea just exposed: "to train as the game is played."

\section{The Nordic Hamstring Exercise}

Concerning the exercises to be included in an effectiveness prevention program, it is undoubtedly worth mentioning the Nordic hamstring exercise (NHE), which is the only exercise showing a good validation. ${ }^{79,140-143}$ A regular practice of NHE results in an increase of the eccentric strength of hamstring, ${ }^{143}$ its execution requires no special equipment and, therefore, it can be easily included into the normal routine exercises on the field (-Table 1). However, it is important to remember that soccer players in particular (but also athletes in general) have a poor compliance for a regular training plan of preventive exercises, and for that the exercises should always be performed under the supervision of a qualified trainer. ${ }^{144}$ Furthermore, an interesting aspect of the NHE is that it represents also an excellent test to subdivide the subjects into two different categories according to the hamstring eccentric force. The discriminating factor is to be able or not to reach and maintain a proper execution just to a 30-degree angle joint measured at the knee joint level. Therefore, the two categories are: In the first category, we will insert the subjects defined as "having a good hamstring functionality" and able to reach a knee joint angle equal to 30 degrees, simultaneously maintaining a correct exercise execution. ${ }^{79}$ In the second category, we will include all the subjects defined as "not having a good hamstring functionality" and unable to maintain a correct execution of the exercise until the achievement of 30-degree knee joint angle. ${ }^{79}$

In a RCT, ${ }^{129}$ the introduction of the NHE in a 10 -week duration prevention program reduced the incidence of hamstring injuries as much as $70 \%$, which resulted in line with a previous study of Arnason et al. ${ }^{145}$ More recently, Petersen et al ${ }^{129}$ and van der Horst et al ${ }^{142}$ showed that NHE significantly decreased hamstring injuries in Danish elite, subelite, and amateur players and in Dutch amateur players, respectively.

The interest of the NHE lies mainly in the fact that during its execution it is possible to get a high hamstring activation, rather than during the execution of other more common exercises focused on the thigh flexor muscles. ${ }^{146}$ The peak of activation, measured by electromyogram (EMG), is recorded in the final part of the movement (i.e., in almost extended knees). This data emphasizes the importance of carrying out the NHE through complete range of motion (ROM). ${ }^{105}$

In a study conducted over 24 soccer teams for a total of over 650 professional players and during a period of 4 years, Arnason et $\mathrm{al}^{145}$ showed that in teams where NHE was coupled with a stretching program the hamstring injuries decreased by approximately $65 \%$. These data underline the importance of adopting multicomponent prevention programs (i.e., based on multiple complementary prevention exercises) as already suggested by Owen et al. ${ }^{147}$ Indeed, one of the NHE limit is represented by its monoarticular execution (i.e., involving only the knee joint, and the subjects do not perform a hip flexion) while the hamstring biomechanical injury risk occurs during a simultaneous extension of hip and knee joint. ${ }^{34,38-41}$ For this reason, it is necessary to 
combine the NHE to other exercises to correct this deficiency. ${ }^{147}$

Moreover, it is interesting to note that during NHE the EMG shows both the dominant and the nondominant limbs equally involved. Moreover, NHE, if performed in a systematic way, can increase the hamstring eccentric peak force by a percentage exciding 20\%. ${ }^{105}$ Regarding the frequency with which the NHE should be proposed, some authors recommend its execution for three sessions per week. ${ }^{148}$ The NHE can be made progressively more challenging adopting a slight overload, such as a ballasted jacket, or an external push made by the mate. The difficulty increase is recommended when the athlete is able to perform 12 repetitions at full ROM while maintaining a correct execution.

Beyond the obvious benefits that can be drawn from a systematic practice of NHE, it is also important to underline some limits. In NHE the hamstring complex is stressed in monoarticular modality, while during most injuries movements the hamstring complex is stressed in a biarticular way involving both knee and hip joints. During NHE, as described in the literature, the hip joint is not involved as movement is exclusively performed at the knee joint level. These biomechanical limits strongly suggest the use of the NHE as part of a broader rehabilitation program which also incorporates hamstring biarticular exercises, ${ }^{146}$ or the possibility to modify the NHE to incorporate hip joint movements. Unfortunately, to date the implementation of NHE into the injury prevention program of professional soccer in Europe is, to our knowledge, too low to reasonably expect a positive effect on hamstring injuries. ${ }^{149}$

\section{BF, SM, and ST: Do Different Biomechanical Tasks Require Different Prevention and Rehabilitation Programs?}

As already discussed, the injury mechanisms determining the $\mathrm{BF}$ and SM lesions are substantially different. For BF, the most important injury risk is the excessive elongation, ${ }^{34,38-41}$ while for SM it seems more to be the excessive strength production. $^{35,42,43}$ These etiological differences would justify a difference concerning both the rehabilitation and prevention programs. Therefore, the prevention (and rehabilitation) programs for BF should be focused on stretching conditioning (i.e., with exercises during which the muscle produces eccentric force in stretching condition), while the SM prevention (and rehabilitation) programs should be focused on strengthening.

Askling et $\mathrm{al}^{150}$ showed the superiority of a rehabilitation program for BF based on stretching conditioning compared with a classical rehabilitation program. Concerning the prevention programs, systematically performing exercises in elongation conditions may be able to change the muscle's optimal length increasing this latter, thereby preventing possible injuries. ${ }^{151}$ Therefore, this type of exercise called "eccentric faster contraction in elongated position (EFCEP)" (i.e., eccentric strengthening exercises in situations of muscle lengthening) may represent an interesting prevention strategy for $\mathrm{BF}^{34,38}$

Concerning ST, since its biomechanical role is doublethat is, as the BF shows an important eccentric activation into the middle swing to initial stance phase $\mathrm{e}^{41,44,45}$ and it plays an important role in strength production ${ }^{46}$-the specific prevention program may be based on both these two aspects (i.e., eccentric strengthening exercises in situations of muscle lengthening and concentric strengthening).

\section{The Isokinetic Training and Testing}

In literature, we can generally find three different velocities at which the hamstring peak torque has been assessed: 60 , 180. and $300^{\circ} / \mathrm{s} .{ }^{152}$ Some studies highly recommend to consider the peak torque recorded at $300^{\circ} / \mathrm{s}$ since this value is closer as to the angular velocities developed during sport activities. ${ }^{73}$ Nevertheless, it is important to note that many sport movements are performed at much higher speeds. Indeed, the soccer kick is performed at angular speeds clearly above $1,200^{\circ} / \mathrm{s}$ at the knee joint level. ${ }^{61,153,154}$ In any case, the proposed protocols lack a correct validation. ${ }^{73,155}$ However, the isokinetic training in eccentric modality showed a good efficacy concerning both hamstring prevention and rehabilitation. ${ }^{67,91,156}$ Furthermore, its high reproducibility represents an optimal method to assess the hamstring strength value and the hamstring/Q ratio. ${ }^{91,152}$

\section{Isoinertial Training}

Recently, some devices based on the so-called "isoinertial technology" (IT) appeared. Interest for this particular training dates back to the late 1980s of last century, a period in which IT was brought to the field as a training method for muscular conditioning of astronauts engaged in long space travels. The IT devices used a specific flywheel that allows muscular training even in the absence of gravity. ${ }^{157,158}$ The most important difference between the IT and the classical isotonic technology (CIT) is that in CIT the external resistance is constant and is represented by the load, while in the IT the external resistance depends on the acceleration produced by the subject on the flywheel and is therefore variable. Some studies reported the validity of IT concerning the hamstring prevention programs. ${ }^{159-163}$ However, it is important to underline that other studies ${ }^{141,145}$ showed that the important delayed muscle soreness caused by IT can produce an important loss of compliance for this type of training.

\section{Future Directions}

Given the importance of the hamstring strengthening, especially concerning eccentric strength, in hamstring injuries prevention research it is paramount to determine accurately the frequency, the intensity, and the total load of the prevention plans in relationship with the total technical training amount, to avoid overloads.

The exercises proposed both in PP and SP plans must try to adapt as much as possible to the specific performance model in respect to the concept: "to train as the game is played," with all the caution to be kept when strictly applying this concept to the whole training program. 
The efficacy of muscle injuries prevention program is strongly linked to the consciousness of the coaches regarding this topic. Indeed, coach and coaching staff decide the content of the training sessions with the related training load and too often they are not available to devote a part of training to injuries prevention programs. ${ }^{164,165}$ This represents an important point to improve to fill the gap existing between research and field practice. ${ }^{166}$

Another factor to consider regarding the efficacy of injuries prevention programs is the stability of both medical and coaching staffs. ${ }^{167}$ In soccer, it is quite rare to obtain a coaching staff stability but, on the contrary, it is possible and most likely to create into the club a continuity concerning the medical staff. This might guarantee efficiency of injuries prevention programs.

Both the PP and SP plans must be designed with respect to the different biomechanical behavior of the three different muscles composing the hamstring muscular complex.

Some aspects like EFCEP methodology, the efficacy of stretching exercises, and the specific technical training methodology need further investigations.

\section{Conclusion}

In general, to design a prevention protocol it is necessary to follow basic anatomical, biomechanical, and physiological key points. This is particularly important for a hamstring injury prevention protocol. Indeed, the hamstring complex biomechanical function shall consider the different biomechanical behaviors of BF, SM, and ST. Another key point is the movement biomechanics of the situations that threaten hamstring integrity. Only by respecting the principle of the "specificity" it will be possible to optimize the prevention programs' outcome.

\section{Conflict of Interest}

None declared.

\section{References}

1 Hawkins RD, Hulse MA, Wilkinson C, Hodson A, Gibson M. The association football medical research programme: an audit of injuries in professional football. Br J Sports Med 2001;35(01): 43-47

2 Morgan BE, Oberlander MA. An examination of injuries in major league soccer. The inaugural season. Am J Sports Med 2001;29 (04):426-430

3 Junge A, Dvorak J, Graf-Baumann T, Peterson L. Football injuries during FIFA tournaments and the Olympic Games, 1998-2001: development and implementation of an injury-reporting system. Am J Sports Med 2004;32(1, Suppl):80S-89S

4 Woods C, Hawkins RD, Maltby S, Hulse M, Thomas A, Hodson A; Football Association Medical Research Programme. The Football Association Medical Research Programme: an audit of injuries in professional football-analysis of hamstring injuries. $\mathrm{Br} \mathrm{J}$ Sports Med 2004;38(01):36-41

5 Morgan DL. New insights into the behavior of muscle during active lengthening. Biophys J 1990;57(02):209-221

6 Kujala UM, Orava S, Järvinen M. Hamstring injuries. Current trends in treatment and prevention. Sports Med 1997;23(06): 397-404
7 Hawkins RD, Hulse MA, Wilkinson C, Hodson A, Gibson M. The association football medical research programme: an audit of injuries in professional football. Br J Sports Med 2001;35(01): 43-47

8 Ekstrand J, Hägglund M, Waldén M. Epidemiology of muscle injuries in professional football (soccer). Am J Sports Med 2011a39(06):1226-1232

9 Ekstrand J, Hägglund M, Waldén M. Injury incidence and injury patterns in professional football: the UEFA injury study. Br J Sports Med 2011b45(07):553-558

10 Orchard J, Seward H. Epidemiology of injuries in the Australian Football League, seasons 1997-2000. Br J Sports Med 2002;36 (01):39-44

11 Orchard J, Seward H. AFL injury report 2003. J Sci Med Sport 2004; 7:264-265

12 Orchard JW, Seward H, Orchard JJ. Results of 2 decades of injury surveillance and public release of data in the Australian Football League. Am J Sports Med 2013;41(04):734-741

13 Orchard J, Marsden J, Lord S, Garlick D. Preseason hamstring muscle weakness associated with hamstring muscle injury in Australian footballers. Am J Sports Med 1997;25(01):81-85

14 Junge A, Engebretsen L, Mountjoy ML, et al. Sports injuries during the Summer Olympic Games 2008. Am J Sports Med 2009;37 (11):2165-2172

15 Alonso JM, Junge A, Renström P, Engebretsen L, Mountjoy M, Dvorak J. Sports injuries surveillance during the 2007 IAAF World Athletics Championships. Clin J Sport Med 2009;19(01): 26-32

16 Alonso JM, Tscholl PM, Engebretsen L, Mountjoy M, Dvorak J, Junge A. Occurrence of injuries and illnesses during the 2009 IAAF World Athletics Championships. Br J Sports Med 2010;44 (15):1100-1105

17 Brooks JHM, Fuller CW, Kemp SPT, Reddin DB. Epidemiology of injuries in English professional rugby union: part 1 match injuries. Br J Sports Med 2005;39(10):757-766

18 Brooks JHM, Fuller CW, Kemp SPT, Reddin DB. A prospective study of injuries and training amongst the England 2003 Rugby World Cup squad. Br J Sports Med 2005;39(05):288-293

19 Brooks JHM, Fuller CW, Kemp SPT, Reddin DB. Incidence, risk, and prevention of hamstring muscle injuries in professional rugby union. Am J Sports Med 2006;34(08):1297-1306

20 Askling C, Lund H, Saartok T, Thorstensson A. Self-reported hamstring injuries in student-dancers. Scand J Med Sci Sports 2002;12(04):230-235

21 Sallay PI, Friedman RL, Coogan PG, Garrett WE. Hamstring muscle injuries among water skiers. Functional outcome and prevention. Am J Sports Med 1996;24(02):130-136

22 Orchard JW, James T, Portus MR. Injuries to elite male cricketers in Australia over a 10-year period. J Sci Med Sport 2006;9(06): 459-467

23 Ekstrand J, Waldén M, Hägglund M. Hamstring injuries have increased by $4 \%$ annually in men's professional football, since 2001: a 13-year longitudinal analysis of the UEFA Elite Club injury study. Br J Sports Med 2016;50(12):731-737

24 Barnes C, Archer DT, Hogg B, Bush M, Bradley PS. The evolution of physical and technical performance parameters in the English Premier League. Int J Sports Med 2014;35(13):1095-1100

25 Verrall GM, Slavotinek JP, Barnes PG, Fon GT. Diagnostic and prognostic value of clinical findings in 83 athletes with posterior thigh injury: comparison of clinical findings with magnetic resonance imaging documentation of hamstring muscle strain. Am J Sports Med 2003;31(06):969-973

26 Gabbe BJ, Finch CF, Bennell KL, Wajswelner H. Risk factors for hamstring injuries in community level Australian football. Br J Sports Med 2005;39(02):106-110

27 Gabbe BJ, Bennell KL, Finch CF, Wajswelner H, Orchard JW. Predictors of hamstring injury at the elite level of Australian football. Scand J Med Sci Sports 2006;16(01):7-13 
28 Gabbe BJ, Bennell KL, Finch CF. Why are older Australian football players at greater risk of hamstring injury? J Sci Med Sport 2006; 9(04):327-333

29 Seward H, Orchard J, Hazard H, Collinson D. Football injuries in Australia at the élite level. Med J Aust 1993;159(05):298-301

30 van Wingerden JP, Vleeming A, Buyruk HM, Raissadat K. Stabilization of the sacroiliac joint in vivo: verification of muscular contribution to force closure of the pelvis. Eur Spine J 2004;13 (03):199-205

31 Heiser TM, Weber J, Sullivan G, Clare P, Jacobs RR. Prophylaxis and management of hamstring muscle injuries in intercollegiate football players. Am J Sports Med 1984;12(05):368-370

32 Brockett CL, Morgan DL, Proske U. Human hamstring muscles adapt to eccentric exercise by changing optimum length. Med Sci Sports Exerc 2001;33(05):783-790

33 Feeley BT, Kennelly S, Barnes RP, et al. Epidemiology of National Football League training camp injuries from 1998 to 2007. Am J Sports Med 2008;36(08):1597-1603

34 Schache AG, Dorn TW, Blanch PD, Brown NA, Pandy MG. Mechanics of the human hamstring muscles during sprinting. Med Sci Sports Exerc 2012;44(04):647-658

35 Askling C, Saartok T, Thorstensson A. Type of acute hamstring strain affects flexibility, strength, and time to return to preinjury level. Br J Sports Med 2006;40(01):40-44

36 Clanton TO, Coupe KJ. Hamstring strains in athletes: diagnosis and treatment. J Am Acad Orthop Surg 1998;6(04):237-248

37 Drezner JA. Practical management: hamstring muscle injuries. Clin J Sport Med 2003;13(01):48-52

38 Chumanov ES, Heiderscheit BC, Thelen DG. The effect of speed and influence of individual muscles on hamstring mechanics during the swing phase of sprinting. J Biomech 2007;40(16): 3555-3562

39 Chumanov ES, Heiderscheit BC, Thelen DG. Hamstring musculotendon dynamics during stance and swing phases of highspeed running. Med Sci Sports Exerc 2011;43(03):525-532

40 Schache AG, Wrigley TV, Baker R, Pandy MG. Biomechanical response to hamstring muscle strain injury. Gait Posture 2009; 29(02):332-338

41 Schache AG, Dorn TW, Wrigley TV, Brown NA, Pandy MG. Stretch and activation of the human biarticular hamstrings across a range of running speeds. Eur J Appl Physiol 2013;113(11): 2813-2828

42 Askling CM, Tengvar M, Saartok T, Thorstensson A. Acute firsttime hamstring strains during slow-speed stretching: clinical, magnetic resonance imaging, and recovery characteristics. Am J Sports Med 2007;35(10):1716-1724

43 Askling CM, Tengvar M, Saartok T, Thorstensson A. Acute firsttime hamstring strains during high-speed running: a longitudinal study including clinical and magnetic resonance imaging findings. Am J Sports Med 2007;35(02):197-206

44 Onishi H, Yagi R, Oyama M, Akasaka K, Ihashi K, Handa Y. EMGangle relationship of the hamstring muscles during maximum knee flexion. J Electromyogr Kinesiol 2002;12(05):399-406

45 Higashihara A, Ono T, Kubota J, Okuwaki T, Fukubayashi T. Functional differences in the activity of the hamstring muscles with increasing running speed. J Sports Sci 2010;28(10): 1085-1092

46 Schuermans J, Van Tiggelen D, Danneels L, Witvrouw E. Biceps femoris and semitendinosus-teammates or competitors? New insights into hamstring injury mechanisms in male football players: a muscle functional MRI study. Br J Sports Med 2014; 48(22):1599-1606

47 Koulouris G, Connell DA, Brukner P, Schneider-Kolsky M. Magnetic resonance imaging parameters for assessing risk of recurrent hamstring injuries in elite athletes. Am J Sports Med 2007; 35(09):1500-1506

48 Ekstrand J, Healy JC, Waldén M, Lee JC, English B, Hägglund M. Hamstring muscle injuries in professional football: the correla- tion of MRI findings with return to play. Br J Sports Med 2012;46 (02):112-117

49 Feucht MJ, Plath JE, Seppel G, Hinterwimmer S, Imhoff AB, Brucker PU. Gross anatomical and dimensional characteristics of the proximal hamstring origin. Knee Surg Sports Traumatol Arthrosc 2015;23(09):2576-2582

50 van der Made AD, Wieldraaijer T, Kerkhoffs GM, et al. The hamstring muscle complex. Knee Surg Sports Traumatol Arthrosc 2015;23(07):2115-2122

51 Volpi P, Bisciotti GN. The hamstring muscles: anatomy, biomechanics and risk injury. Med Sport (Roma) 2016;69(02):297-307

52 Brukner P, Nealon A, Morgan C, Burgess D, Dunn A. Recurrent hamstring muscle injury: applying the limited evidence in the professional football setting with a seven-point programme. Br J Sports Med 2014;48(11):929-938

53 Verrall GM, Slavotinek JP, Barnes PG, Fon GT, Spriggins AJ. Clinical risk factors for hamstring muscle strain injury: a prospective study with correlation of injury by magnetic resonance imaging. Br J Sports Med 2001;35(06):435-439, discussion 440

54 Arnason A, Sigurdsson SB, Gudmundsson A, Holme I, Engebretsen L, Bahr R. Risk factors for injuries in football. Am J Sports Med 2004;32(1, Suppl):5S-16S

55 Gabbe BJ, Branson R, Bennell KL. A pilot randomised controlled trial of eccentric exercise to prevent hamstring injuries in community-level Australian Football. J Sci Med Sport 2006;9 (1-2):103-109

56 Arnason A, Sigurdsson SB, Gudmundsson A, Holme I, Engebretsen $\mathrm{L}$, Bahr R. Physical fitness, injuries, and team performance in soccer. Med Sci Sports Exerc 2004;36(02):278-285

57 Hägglund M, Waldén M, Ekstrand J. Previous injury as a risk factor for injury in elite football: a prospective study over two consecutive seasons. Br J Sports Med 2006;40(09):767-772

58 Koulouris G, Connell D. Evaluation of the hamstring muscle complex following acute injury. Skeletal Radiol 2003;32(10): 582-589

59 Silvers HJ, Mandelbaum BR. Prevention of anterior cruciate ligament injury in the female athlete. Br J Sports Med 2007;41 (Suppl 1):i52-i59

60 Garrett WE Jr. Muscle strain injuries: clinical and basic aspects. Med Sci Sports Exerc 1990;22(04):436-443

61 Lieber RL, Woodburn TM, Fridén J. Muscle damage induced by eccentric contractions of 25\% strain. J Appl Physiol (1985) 1991; 70(06):2498-2507

62 Greig M, Siegler JC. Soccer-specific fatigue and eccentric hamstrings muscle strength. J Athl Train 2009;44(02):180-184

63 Hawkins RD, Fuller CW. Risk assessment in professional football: an examination of accidents and incidents in the 1994 World Cup finals. Br J Sports Med 1996;30(02):165-170

64 Lüthje P, Nurmi I, Kataja M, et al. Epidemiology and traumatology of injuries in elite soccer: a prospective study in Finland. Scand J Med Sci Sports 1996;6(03):180-185

65 Yoon YS, Chai M, Shin DW. Football injuries at Asian tournaments. Am J Sports Med 2004;32(1, Suppl):36S-42S

66 Thelen DG, Chumanov ES, Hoerth DM, et al. Hamstring muscle kinematics during treadmill sprinting. Med Sci Sports Exerc 2005;37(01):108-114

67 Croisier JL, Ganteaume S, Binet J, Genty M, Ferret JM. Strength imbalances and prevention of hamstring injury in professional soccer players: a prospective study. Am J Sports Med 2008;36 (08):1469-1475

68 Fousekis K, Tsepis E, Poulmedis P, Athanasopoulos S, Vagenas G. Intrinsic risk factors of non-contact quadriceps and hamstring strains in soccer: a prospective study of 100 professional players. Br J Sports Med 2011;45(09):709-714

69 van Beijsterveldt AM, van de Port IG, Vereijken AJ, Backx FJ. Risk factors for hamstring injuries in male soccer players: a systematic review of prospective studies. Scand J Med Sci Sports 2013; 23(03):253-262 
70 Croisier JL, Forthomme B, Namurois MH, Vanderthommen M, Crielaard JM. Hamstring muscle strain recurrence and strength performance disorders. Am J Sports Med 2002;30(02): 199-203

71 Aagaard P, Simonsen EB, Trolle M, Bangsbo J, Klausen K. Isokinetic hamstring/quadriceps strength ratio: influence from joint angular velocity, gravity correction and contraction mode. Acta Physiol Scand 1995; 154(04):421-427

72 Taylor DC, Dalton JD Jr, Seaber AV, Garrett WE Jr. Experimental muscle strain injury. Early functional and structural deficits and the increased risk for reinjury. Am J Sports Med 1993;21(02): 190-194

73 Bennell K, Wajswelner H, Lew P, et al. Isokinetic strength testing does not predict hamstring injury in Australian Rules footballers. Br J Sports Med 1998;32(04):309-314

74 Orchard JW. Intrinsic and extrinsic risk factors for muscle strains in Australian football. Am J Sports Med 2001;29(03):300-303

75 Murphy DF, Connolly DA, Beynnon BD. Risk factors for lower extremity injury: a review of the literature. $\mathrm{Br}$ J Sports Med 2003; 37(01):13-29

76 Croisier JL. Factors associated with recurrent hamstring injuries. Sports Med 2004;34(10):681-695

77 Fuller CW, Bahr R, Dick RW, Meeuwisse WH. A framework for recording recurrences, reinjuries, and exacerbations in injury surveillance. Clin J Sport Med 2007;17(03):197-200

78 Prior M, Guerin M, Grimmer K. An evidence-based approach to hamstring strain injury: a systematic review of the literature. Sports Health 2009;1(02):154-164

79 Engebretsen AH, Myklebust G, Holme I, Engebretsen L, Bahr R. Intrinsic risk factors for hamstring injuries among male soccer players: a prospective cohort study. Am J Sports Med 2010;38 (06):1147-1153

80 Warren P, Gabbe BJ, Schneider-Kolsky M, Bennell KL. Clinical predictors of time to return to competition and of recurrence following hamstring strain in elite Australian footballers. Br J Sports Med 2010;44(06):415-419

81 Mendiguchia J, Alentorn-Geli E, Brughelli M. Hamstring strain injuries: are we heading in the right direction? Br J Sports Med 2012;46(02):81-85

82 Opar DA, Williams MD, Shield AJ. Hamstring strain injuries: factors that lead to injury and re-injury. Sports Med 2012;42 (03):209-226

83 Verrall GM, Slavotinek JP, Barnes PG, Fon GT, Esterman A. Assessment of physical examination and magnetic resonance imaging findings of hamstring injury as predictors for recurrent injury. J Orthop Sports Phys Ther 2006;36(04):215-224

84 Malliaropoulos N, Isinkaye T, Tsitas K, Maffulli N. Reinjury after acute posterior thigh muscle injuries in elite track and field athletes. Am J Sports Med 2011;39(02):304-310

85 Agre JC. Hamstring injuries. Proposed aetiological factors, prevention, and treatment. Sports Med 1985;2(01):21-33

86 Jönhagen S, Németh G, Eriksson E. Hamstring injuries in sprinters. The role of concentric and eccentric hamstring muscle strength and flexibility. Am J Sports Med 1994;22(02):262-266

87 Dvorak J, Junge A. Football injuries and physical symptoms. A review of the literature. Am J Sports Med 2000;28(5, Suppl): S3-S9

88 Brukner P, Khan K. Clinical Sports Medicine. Sydney: McGrawHill Book Company; 1997:168-169

89 Brockett CL, Morgan DL, Proske U. Predicting hamstring strain injury in elite athletes. Med Sci Sports Exerc 2004;36(03): 379-387

90 Kääriäinen M, Järvinen T, Järvinen M, Rantanen J, Kalimo H. Relation between myofibers and connective tissue during muscle injury repair. Scand J Med Sci Sports 2000;10(06):332-337

91 Proske U, Morgan DL, Brockett CL, Percival P. Identifying athletes at risk of hamstring strains and how to protect them. Clin Exp Pharmacol Physiol 2004;31(08):546-550
92 Hennessey L, Watson AW. Flexibility and posture assessment in relation to hamstring injury. BrJSports Med 1993;27(04):243-246

93 Worrell TW. Factors associated with hamstring injuries. An approach to treatment and preventative measures. Sports Med 1994;17(05):338-345

94 Clark RA. Hamstring injuries: risk assessment and injury prevention. Ann Acad Med Singapore 2008;37(04):341-346

95 Söderman K, Adolphson J, Lorentzon R, Alfredson H. Injuries in adolescent female players in European football: a prospective study over one outdoor soccer season. Scand J Med Sci Sports 2001;11(05):299-304

96 Cvjetkovic DD, Bijeljac S, Palija S, et al. Isokinetic testing in evaluation rehabilitation outcome after ACL reconstruction. Med Arh 2015;69(01):21-23

97 Harput G, Kilinc HE, Ozer H, Baltaci G, Mattacola CG. Quadriceps and hamstring strength recovery during early neuromuscular rehabilitation after ACL hamstring-tendon autograft reconstruction. J Sport Rehabil 2015;24(04):398-404

98 Bisciotti GN. Il concetto del Puzzle. Sports Med 2003;1:51-57

99 Bisciotti GN. Il corpo in movimento. Milano: Edizioni Correre; 2003:132-133

100 Witvrouw E, Danneels L, Asselman P, D'Have T, Cambier D. Muscle flexibility as a risk factor for developing muscle injuries in male professional soccer players. A prospective study. Am J Sports Med 2003;31(01):41-46

101 Ekstrand J, Gillquist J, Möller M, Oberg B, Liljedahl SO. Incidence of soccer injuries and their relation to training and team success. Am J Sports Med 1983;11(02):63-67

102 Ekstrand J, Gillquist J. Soccer injuries and their mechanisms: a prospective study. Med Sci Sports Exerc 1983;15(03):267-270

103 Dadebo B, White J, George KP. A survey of flexibility training protocols and hamstring strains in professional football clubs in England. Br J Sports Med 2004;38(04):388-394

104 O'Sullivan K, McAuliffe S, Deburca N. The effects of eccentric training on lower limb flexibility: a systematic review. $\mathrm{Br} J$ Sports Med 2012;46(12):838-845

105 Brughelli M, Cronin J. Altering the length-tension relationship with eccentric exercise : implications for performance and injury. Sports Med 2007;37(09):807-826

106 Hartig DE, Henderson JM. Increasing hamstring flexibility decreases lower extremity overuse injuries in military basic trainees. Am J Sports Med 1999;27(02):173-176

107 Sherry MA, Best TM. A comparison of 2 rehabilitation programs in the treatment of acute hamstring strains. J Orthop Sports Phys Ther 2004;34(03):116-125

108 Cameron ML, Adams RD, Maher CG, Misson D. Effect of the HamSprint Drills training programme on lower limb neuromuscular control in Australian football players. J Sci Med Sport 2009; 12(01):24-30

109 Silder A, Sherry MA, Sanfilippo J, Tuite MJ, Hetzel SJ, Heiderscheit BC. Clinical and morphological changes following 2 rehabilitation programs for acute hamstring strain injuries: a randomized clinical trial. J Orthop Sports Phys Ther 2013;43(05):284-299

110 Bisciotti GN. Le lesioni muscolari. Biologia, eziologia e trattamento. Perugia: Calzetti e Mariucci; 2010

111 Safran MR, Garrett WE Jr, Seaber AV, Glisson RR, Ribbeck BM. The role of warmup in muscular injury prevention. Am J Sports Med 1988;16(02):123-129

112 Noonan TJ, Best TM, Seaber AV, Garrett WE Jr. Thermal effects on skeletal muscle tensile behavior. Am J Sports Med 1993;21(04): 517-522

113 Magnusson SP, Simonsen EB, Aagaard P, Gleim GW, McHugh MP, Kjaer M. Viscoelastic response to repeated static stretching in the human hamstring muscle. Scand J Med Sci Sports 1995;5(06): 342-347

114 Dvorak J, Junge A, Chomiak J, et al. Risk factor analysis for injuries in football players. Possibilities for a prevention program. Am J Sports Med 2000;28(5, Suppl):S69-S74 
115 Mair SD, Seaber AV, Glisson RR, Garrett WE Jr. The role of fatigue in susceptibility to acute muscle strain injury. Am J Sports Med 1996;24(02):137-143

116 Dellal A, Lago-Peñas C, Rey E, Chamari K, Orhant E. The effects of a congested fixture period on physical performance, technical activity and injury rate during matches in a professional soccer team. Br J Sports Med 2015;49(06):390-394

117 Bengtsson H, Ekstrand J, Hägglund M. Muscle injury rates in professional football increase with fixture congestion: an 11year follow-up of the UEFA Champions League injury study. $\mathrm{Br} \mathrm{J}$ Sports Med 2013;47(12):743-747

118 Bishop D, Edge J, Thomas C, Mercier J. Effects of high-intensity training on muscle lactate transporters and postexercise recovery of muscle lactate and hydrogen ions in women. Am J Physiol Regul Integr Comp Physiol 2008;295(06):R1991-R1998

119 Roe GA, Darrall-Jones JD, Till K, Jones B. Preseason changes in markers of lower body fatigue and performance in young professional rugby union players. Eur J Sport Sci 2016;16(08): 981-988

120 Haseler LJ, Hogan MC, Richardson RS. Skeletal muscle phosphocreatine recovery in exercise-trained humans is dependent on O2 availability. J Appl Physiol (1985) 1999;86(06):2013-2018

121 Eirale C, Bisciotti GN, Fiorella T, Sannicandro I. Profilo della performance in calciatori italiani d'elite. Med Sport (Roma) 2011;64(03):243-256

122 Chamari K, Bahr R. Training for elite sport performance: injury risk management also matters!. Int J Sports Physiol Perform 2016;11(05):561-562

123 Cross KM, Worrell TW. Effects of a static stretching program on the incidence of lower extremity musculotendinous strains. J Athl Train 1999;34(01):11-14

124 Weldon SM, Hill RH. The efficacy of stretching for prevention of exercise-related injury: a systematic review of the literature. Man Ther 2003;8(03):141-150

125 Verrall GM, Slavotinek JP, Barnes PG. The effect of sports specific training on reducing the incidence of hamstring injuries in professional Australian Rules football players. Br J Sports Med 2005;39(06):363-368

126 Heiderscheit BC, Hoerth DM, Chumanov ES, Swanson SC, Thelen BJ, Thelen DG. Identifying the time of occurrence of a hamstring strain injury during treadmill running: a case study. Clin Biomech (Bristol, Avon) 2005;20(10):1072-1078

127 Heiderscheit BC, Sherry MA, Silder A, Chumanov ES, Thelen DG. Hamstring strain injuries: recommendations for diagnosis, rehabilitation, and injury prevention. J Orthop Sports Phys Ther 2010;40(02):67-81

128 Clark R, Bryant A, Culgan JP, Hartley B. The effects of eccentric hamstring strength training on dynamic performance and isokinetic strength parameters: a pilot study on the implication for the prevention of hamstring injuries. Phys Ther Sport 2005; 6:67-73

129 Petersen J, Thorborg K, Nielsen MB, Budtz-Jørgensen E, Hölmich $P$. Preventive effect of eccentric training on acute hamstring injuries in men's soccer: a cluster-randomized controlled trial. Am J Sports Med 2011;39(11):2296-2303

130 Naclerio F, Faigenbaum AD, Larumbe E, et al. Effects of a low volume injury prevention program on the hamstring torque angle relationship. Res Sports Med 2013;21(03):253-263

131 Seagrave RA III, Perez L, McQueeney S, Toby EB, Key V, Nelson JD. Preventive effects of eccentric training on acute hamstring muscle injury in professional baseball. Orthop J Sports Med 2014;2(06):2325967114535351

132 Shadle IB, Cacolice PA. Eccentric exercises reduce hamstring strains in slite adult male soccer players: a critically appraised topic. J Sport Rehabil 2017;26(06):573-577

133 Holcomb WR, Rubley MD, Lee HJ, Guadagnoli MA. Effect of hamstring-emphasized resistance training on hamstring:quadriceps strength ratios. J Strength Cond Res 2007;21(01):41-47
134 Daneshjoo A, Rahnama N, Mokhtar AH, Yusof A. Effectiveness of injury prevention programs on developing quadriceps and hamstrings strength of young male professional soccer players. J Hum Kinet 2013;39:115-125

135 Valle X, L Tol J, Hamilton B, et al. Hamstring muscle injuries, a rehabilitation protocol purpose. Asian J Sports Med 2015;6(04): e25411

136 Coleman JS. The Mathematics of Collective Action. London: Transaction Publisher; 2007:202-208

137 Verrall GM, Esterman A, Hewett TE. Analysis of the three most prevalent injuries in Australian football demonstrates a season to season association between groin/hip/osteitis pubis injuries with ACL knee injuries. Asian J Sports Med 2014;5(03):e23072

138 Mendiguchia J, Brughelli M. A return-to-sport algorithm for acute hamstring injuries. Phys Ther Sport 2011;12(01):2-14

139 Garrett WE Jr. Muscle strain injuries. Am J Sports Med 1996;24(6, Suppl):S2-S8

140 Arnason A, Gudmundsson A, Dahl HA, Jóhannsson E. Soccer injuries in Iceland. Scand J Med Sci Sports 1996;6(01):40-45

141 Askling C, Karlsson J, Thorstensson A. Hamstring injury occurrence in elite soccer players after preseason strength training with eccentric overload. Scand J Med Sci Sports 2003;13(04): 244-250

142 van der Horst N, Smits DW, Petersen J, Goedhart EA, Backx FJ. The preventive effect of the Nordic hamstring exercise on hamstring injuries in amateur soccer players: a randomized controlled trial. Am J Sports Med 2015;43(06):1316-1323

143 Lovell R, Siegler JC, Knox M, Brennan S, Marshall PW. Acute neuromuscular and performance responses to Nordic hamstring exercises completed before or after football training. J Sports Sci 2016;34(24):2286-2294

144 Engebretsen AH, Myklebust G, Holme I, Engebretsen L, Bahr R. Prevention of injuries among male soccer players: a prospective, randomized intervention study targeting players with previous injuries or reduced function. Am J Sports Med 2008;36(06): 1052-1060

145 Arnason A, Andersen TE, Holme I, Engebretsen L, Bahr R. Prevention of hamstring strains in elite soccer: an intervention study. Scand J Med Sci Sports 2008;18(01):40-48

146 Ebben WP, Leigh DH, Long N, Clewien R, Davies JA. Electromyographical analysis of hamstring resistance training exercises. In: Proceeding of the XXIV International Symposium of the Society of Biomechanics in Sports. 2006, Jul 15; Salzburg (Austria) University of Salzburg; 236-239

147 Owen A, Wong DP, Paul D, Dellal A. Physical and technical comparisons between small, medium and large-sided training games within elite professional soccer. Int J Sports Med 2014; 35:286-282

148 Malliaropoulos N, Mendiguchia J, Pehlivanidis H, et al. Hamstring exercises for track and field athletes: injury and exercise biomechanics, and possible implications for exercise selection and primary prevention. Br J Sports Med 2012;46(12):846-851

149 Bahr R, Thorborg K, Ekstrand J. Evidence-based hamstring injury prevention is not adopted by the majority of Champions League or Norwegian Premier League football teams: the Nordic Hamstring survey. Br J Sports Med 2015;49(22):1466-1471

150 Askling CM, Tengvar M, Thorstensson A. Acute hamstring injuries in Swedish elite football: a prospective randomised controlled clinical trial comparing two rehabilitation protocols. Br J Sports Med 2013;47(15):953-959

151 Witvrouw E, Wangesten A. Hamstring rehabilitation. Science or expert practice? ASPETAR Sport Med J 2013;2:478-485

152 Foreman KT, Addy T, Baker S, Burns J, Hill N, Madden T. Prospective studies into the causation of hamstring injuries in sport: a systematic review. Phys Ther Sport 2006;7:101-109

153 Nunome H, Lake M, Georgakis A, Stergioulas LK. Impact phase kinematics of instep kicking in soccer. J Sports Sci 2006;24(01): $11-22$ 
154 Lees A, Asai T, Andersen TB, Nunome H, Sterzing T. The biomechanics of kicking in soccer: a review. J Sports Sci 2010;28(08): 805-817

155 Bisciotti GN. Per ritrovare la funzionalità. Sports Med 2002; 6:43-47

156 Hibbert O, Cheong K, Grant A, Beers A, Moizumi T. A systematic review of the effectiveness of eccentric strength training in the prevention of hamstring muscle strains in otherwise healthy individuals. N Am J Sports Phys Ther 2008;3(02):67-81

157 Tesch PA, Berg HE. Resistance training in space. Int J Sports Med 1997;18(Suppl 4):S322-S324

158 Tesch PA, Berg HE. Effects of spaceflight on muscle. J Gravit Physiol 1998;5(01):19-22

159 Alkner BA, Tesch PA. Efficacy of a gravity-independent resistance exercise device as a countermeasure to muscle atrophy during 29-day bed rest. Acta Physiol Scand 2004;181(03):345-357

160 Norrbrand L, Pozzo M, Tesch P. Changes in quadriceps muscle volume and strength following 5 weeks of resistance training using a flywheel device vs gravity dependent weights. Proceedings of the 3rd European congress Achievements in Space Medicine into Healthcare Practice and Industry. Berlin, September; 2005

161 Norrbrand L, Tous-Fajardo J, Tesch P. The Squat: iso-inertial resistance exercise promotes greater quadriceps muscle use than the barbell exercise. In 11th Annual Congress of the European College of Sport Science. Lausanne, p. Abstract 1115, 2006

162 Greenwood J, Morrissey MC, Rutherford OM, Narici MV. Comparison of conventional resistance training and the fly-wheel ergometer for training the quadriceps muscle group in patients with unilateral knee injury. Eur J Appl Physiol 2007;101(06): 697-703

163 Haus JM, Carrithers JA, Carroll CC, Tesch PA, Trappe TA. Contractile and connective tissue protein content of human skeletal muscle: effects of 35 and 90 days of simulated microgravity and exercise countermeasures. Am J Physiol Regul Integr Comp Physiol 2007;293(04):R1722-R1727

164 Ekstrand J, Hägglund M, Kristenson K, Magnusson H, Waldén M. Fewer ligament injuries but no preventive effect on muscle injuries and severe injuries: an 11-year follow-up of the UEFA Champions League injury study. Br J Sports Med 2013;47(12): 732-737

165 Gabbett TJ, Kennelly S, Sheehan J, et al. If overuse injury is a 'training load error', should undertraining be viewed the same way? Br J Sports Med 2016;50(17):1017-1018

166 Verhagen E, Voogt N, Bruinsma A, Finch CF. A knowledge transfer scheme to bridge the gap between science and practice: an integration of existing research frameworks into a tool for practice. Br J Sports Med 2014;48(08):698-701

167 Ekstrand J. Preventing injuries in professional football: thinking bigger and working together. Br J Sports Med 2016;50(12): 709-710

168 Mjølsnes R, Arnason A, Østhagen T, Raastad T, Bahr R. A 10-week randomized trial comparing eccentric vs. concentric hamstring strength training in well-trained soccer players. Scand J Med Sci Sports 2004;14(05):311-317 